\title{
Assistência de enfermagem as vítimas de violência sexual
}

\author{
Nursing care as a victim of sexual violence \\ Cuidados de enfermería como víctima de violencia sexual
}

Mikaele Assis Moreira Castro

ORCID: https://orcid.org/0000-0002-7981-0422 Universidade de Palmas, Brasil

E-mail: mikaelecastro@gmail.com

Anna Raquel Araújo Silva

ORCID: https://orcid.org/0000-0001-8441-2835

Universidade Federal do Maranhão, Brasil

E-mail: annaodonto@hotmail.com

Thailane Maria Silva Santana

ORCID: https://orcid.org/0000-0003-0964-6572

Universidade Federal do Maranhão, Brasil

E-mail: Santanathailane@gmail.com

Robson Mariano Oliveira Silva

ORCID: https://orcid.org/0000-0002-3654-5278

Universidade Federal do Maranhão, Brasil

E-mail: Robsomariano.157@gmail.com

Fabrício Ferreira Silva

ORCID: https://orcid.org/0000-0002-4917-7769

Universidade Federal do Maranhão, Brasil

E-mail: proffabricioferreira@outlook.com

Lailton de Sousa Lima

ORCID: https://orcid.org/0000-0001-6672-0121

Universidade Federal do Maranhão, Brasil

E-mail: lailtonlima@outlook.com

Sannaya da Silva Ferreira

ORCID: https://orcid.org/0000-0003-1725-275X

Universidade Federal do Maranhão, Brasil

E-mail: sannayaferreira@ outlook.com

Raylton Aparecido Nascimento Silva

ORCID: https://orcid.org/0000-0003-3832-7685

Universidade Federal de Santa Maria, Brasil

E-mail: rayltonaparecido@gmail.com

Vitor Pachelle Lima Abreu

ORCID: https://orcid.org/0000-0001-9065-3272

Universidade Federal do Tocantins, Brasil

E-mail: vpachelle@gmail.com

Thiago Oliveira Sabino Lima

ORCID: https://orcid.org/0000-0003-2677-9481

Universidade de Palmas, Brasil

E-mail: thiagosabino@uft.edu.br

Ruhena Kelber Abrão Ferreira

ORCID: https://orcid.org/0000-0002-5280-6263

Universidade Federal do Tocantins, Brasil

E-mail: kelberabrao@gmail.com

\begin{abstract}
Resumo
$\mathrm{O}$ trabalho a seguir aborda o tema central como a enfermagem atua frente as vítimas de violência sexual. Objetivo: identificar como a enfermagem acolhe as vítimas; investigar as dificuldades enfrentadas pela equipe de enfermagem; explicar como deve ser feita as notificações dos casos; e compreender a importância do vínculo entre o enfermeiro e as vítimas de violência sexual. Métodos: uma pesquisa baseada em consultas literárias cujos dados são sobre o tema. Sendo utilizado como base de estudos em artigos científicos eletrônicos, pesquisados nas bases de dados da SCIELO, biblioteca virtual da saúde (BVS), artigos acadêmicos. Resultados: a violência sexual é uma das violências mais terríveis que assombra principalmente as mulheres, trazendo grande impacto para saúde sexual e reprodutiva. A enfermagem tem um papel muito importante nos cuidados com vítima, e devem ter empatia e precisam dar apoio, tem que estar preparado para dar a devida assistência às vítimas. Conclui-se que por mais que a violência sexual é antiga, sempre vai existir de formas e modo diferentes, e continua tendo dificuldades por parte da vítima de querer procurar ajuda, e por parte do profissional, pois a maioria não estão preparados para atender.
\end{abstract}

Palavras-chave: Violência sexual; Vítimas de abuso; Assistência de enfermagem. 


\begin{abstract}
The following work addresses the central theme of how nursing works with victims of sexual violence. Objective: to identify how nursing welcomes victims; to investigate the difficulties faced by the nursing team; explain how case notifications should be made; and understand the importance of the bond between nurses and victims of sexual violence. Methods: a research based on literary consultations whose data are on the subject. Being used as a basis for studies in electronic scientific articles, searched in SCIELO databases, virtual health library (VHL), academic articles. Results: sexual violence is one of the most terrible forms of violence that mainly haunts women, with a great impact on sexual and reproductive health. Nursing has a very important role in victim care, and they must have empathy and need to give support, they must be prepared to give proper assistance to victims. It is concluded that, no matter how old sexual violence is, it will always exist in different ways and forms, and it continues to have difficulties on the part of the victim to want to seek help, and on the part of the professional, since most are not prepared to attend. Keywords: Sexual violence; Victims of abuse; Nursing assistance.
\end{abstract}

\title{
Resumen
}

El siguiente trabajo aborda el tema central de cómo la enfermería trabaja con las víctimas de violencia sexual. Objetivo: identificar cómo la enfermería acoge a las víctimas; investigar las dificultades enfrentadas por el equipo de enfermería; explicar cómo se deben hacer las notificaciones de casos; y comprender la importancia del vínculo entre enfermeros y víctimas de violencia sexual. Métodos: una investigación basada en consultas literarias cuyos datos son sobre el tema. Siendo utilizado como base para estudios en artículos científicos electrónicos, consultados en bases de datos SCIELO, biblioteca virtual en salud (BVS), artículos académicos. Resultados: la violencia sexual es una de las formas de violencia más terribles que acecha principalmente a las mujeres, con un gran impacto en la salud sexual y reproductiva. Enfermería tiene un papel muy importante en la atención a las víctimas, deben tener empatía y necesidad de dar apoyo, deben estar preparados para dar una asistencia adecuada a las víctimas. Se concluye que, por muy antigua que sea la violencia sexual, siempre existirá de diferentes maneras y formas, y sigue teniendo dificultades por parte de la víctima para querer buscar ayuda, y por parte del profesional, ya que la mayoría no está preparada para asistir.

Palabras clave: Violencia sexual; Víctimas de violencia sexual; Asistencia de enfermería.

\section{Introdução}

A violência sexual é uma das violências de gênero mais permanente e terrível. Permanente por que acredita-se que a violência sexual persiste desde de muito tempo atrás e ainda ocorre. Por um lado, atinge mulheres, adolescentes e crianças, em todos os espaços sociais, por outro, aterroriza em especial, o imaginário das mulheres, deixando-a mais vulnerável e promovendo uma sensação de constante insegurança, contribuindo para uma cultura violenta (Portela et al, 2014).

A violência é um fenômeno universal, sendo uma das principais causa de morbimortalidade, em especial na população jovem, não havendo restrição de sexo, idade, etnia, raça ou classe social, que ocorreu no passado e atualmente ainda acontece em diferentes contextos ao longo da história (Viodres Inoue, 2008).

Enquanto os homicídios predominam o sexo masculino, a violência sexual atinge principalmente as mulheres e crianças, causando sequelas físicas, sociais, e emocionais, que acaba tornando mais vulneráveis a diversos problemas de saúde (Drezett, 2012).

A violência sexual, acaba acontecendo quando a pessoa tem relação de poder sobre a vítima, por meio de força física, repressão, sedução ou intimidação psicológica, e acaba obrigando a vítima a submeter-se a relação sexual. Essa prática é considerada crime, mesmo sendo exercida por um familiar, seja pai, padrasto, companheiro ou marido (Labronici et al, 2010).

A violência sexual tem um grande impacto para a saúde sexual e reprodutiva tendo como consequência os traumas físicos, doenças sexualmente transmissíveis e a gravidez indesejada. Além disso, acarreta danos psicológicos que acabam produzindo efeitos severos, muitas vezes irreparáveis para a saúde mental, e acaba prejudicando a vítima na sua inserção social (Faria, 2008).

A violência sexual tem maior ocorrência relacionado ao estupro, incluindo aí a categoria de atentado violento ao pudor. A faixa etária de maior ocorrência de estupros é de 10 a 19 anos, seguida de 20 a 29 anos, ou seja, acontece mais na faixa etária que corresponde à infância e à juventude (Huculak, 2017). 
Em relação ao sexo das vítimas, observa-se que, a maioria dos casos atinge as mulheres. A violência sexual foi a mais presente, seguida da violência psicológica e da violência física (Veloso, 2013). A atenção às pessoas em situação de violência sexual não é uma ação isolada deve ser enfrentada com iniciativas que possibilitem ações de atendimento, proteção, prevenção a novas situações e procura medidas para possibilitar a responsabilização dos agressores (Yamamoto, et al 2015).

A inter-relação com a vítima de violência sexual pode ter influência positiva ou negativa. Positiva se houver um atendimento com assistência humanizada, e negativa se for um atendimento discriminatório e preconceituoso. Os profissionais de saúde têm que usar sua experiência e conhecimento científico para esse momento difícil, e precisam dar apoio emocional. Considerando a complexidade e as consequências dessa situação, o atendimento deve ser amplo e integral, havendo necessidade de uma abordagem multiprofissional (Araújo, 2008)

O alvo preferencial deste tipo de violência é a mulher, e tem merecido a atenção de todos os profissionais da saúde, mais o principal e a equipe de enfermagem. Nessa concepção, o primeiro contato da vítima no serviço de saúde deve acontecer com o profissional de enfermagem, que vai oferecer um atendimento humanizado, realizará a anamnese, coleta de materiais para exames laboratoriais, agendamento de retorno e administração de medicamentos. Esses passos que garantem o seguimento ambulatorial (Morais, 2010).

Conhecer a atuação do enfermeiro no atendimento as vítimas de violência sexual.

- Identificar como a enfermagem acolhe as vítimas de violência sexual;

- Investigar as dificuldades enfrentadas pela equipe de enfermagem perante as vítimas;

- Explicar como a equipe de enfermagem deve notificar os casos;

- Compreender a importância do vínculo entre o enfermeiro e a vítima.

\section{Revisão Bibliográfica}

\subsection{História da violência sexual}

O matriarcado foi uma consequência natural da vida em tempos antigos, por não se conhecer o papel do pai na reprodução, o parentesco era restrito como base, a mulher. A sociedade passou a ser patriarcal quando o homem teve consciência do seu papel na reprodução humana, e a fidelidade começou a ser exigida para que os filhos recebessem a herança de seus pais. A partir desse momento, sempre dominou a força masculina sobre as mulheres. Porém, essa autoridade foi confundida com atitudes violentas de todo tipo, física, psicológica e sexual, sendo esta última qualquer ato a participar de relações sexuais pelo uso de força física, intimidação, repressão, chantagem, ameaça (Porto, 2014).

\subsection{Violência sexual no Tocantins}

De acordo com a Secretaria de saúde do governo do Tocantins (2015) o serviço de atenção especializada as pessoas em situação de violência sexual (SAVIS) atende pessoas de todo o estado, em conjunto com os postos de saúde municipais e as delegacias de policias. As vítimas recebem atendimento de urgência quando procuram ajuda em até 72 horas, pois é o período em que a medicação tem eficácia quando administrada. Passados 72 horas é oferecido à vítima atendimento psicossocial e ela passa por exames laboratoriais, e se for preciso recebe tratamento específico (Rodrigues et al, 2020a).

O hospital de referência no estado é o hospital maternidade Dona Regina (HMDR), tendo uma equipe multiprofissional e capacitada no atendimento ambulatorial e de urgência e emergência. Além do Hospital Maternidade Dona Regina tem o hospital materno infantil Tia Dedé que fica em porto nacional que também faz os atendimentos ambulatoriais, e o de urgência e emergência. Nos hospitais de Araguaína e Gurupi estão em fase de implantação (SMS TO, 2015: Rodrigues et al, 2020b) 


\subsection{Impacto para a saúde}

$\mathrm{O}$ atendimento as vítimas de violência sexual têm a necessidade de uma abordagem multiprofissional por causa dos vários problemas que é imposta a vítima. Essa violência pode afetar na saúde física, reprodutiva, mental, emocional e social. Como lesões corporais, IST, HIV/AIDS, gravidez indesejada, fobias, pânico, síndrome do stress pós-traumático, depressão, são bem frequente as vítimas sentir medo da morte, solidão, vergonha e culpa, e ter também problemas familiares e sociais, como separação conjugais, abandona de casa, do emprego, dos estudos e se prostituir entre outros (Abrahão et al, 2007: Rocha et al, 2020).

\subsection{Atendimento às vítimas}

A violência sexual deve ser compreendida de todos os aspectos sociais, culturais, histórico, político, econômico e jurídico, acarretando o uso da força e do poder para a satisfação do desejo sexual. Um dos primeiros profissionais a ter contato com a vítima são os enfermeiros, por isso ele tem um papel muito importante no acolhimento das vítimas integrando as ações da equipe multiprofissional. $\mathrm{O}$ atendimento exige que o profissional garanta a privacidade durante todo acompanhamento e tratamento em todas as unidades de internação que for necessário (SMS SP, 2012).

No Tocantins é oferecido dois tipos de atendimento: o agudo que consiste em tratar a vítima que procura o Serviço de Atenção Especializada as Pessoas em Situação de Violência Sexual (SAVIS), em até 72 horas após a violência por meio de administração de medicamentos garantindo a eficácia de contaminação de IST’S e pílula de emergência para evitar gravidez indesejada. E o atendimento crônico que é quando a vítima sofreu a violência no passado ou sofre constantemente, nesse caso a medicação não é administrada, mas é oferecido atendimento psicossocial, e a vítima passa por exames laboratoriais, e se for preciso receber tratamento específico (SMS TO, 2015: Gomes, Ferreira, Rodrigues, 2020)

É também parte do atendimento que o profissional identifique que tipo de violência, realizar medicação, tratar os problemas que resultou da violência, acompanhar o paciente pelo menos até os seis meses da ocorrência, encaminhar para o serviço de saúde adequado para a necessidade do paciente e notificar a violência (Delziovo et al, 2018).

\subsection{Diagnostico da violência sexual}

Para auxiliar no diagnóstico, o Ministério da Saúde e a Organização Mundial de Saúde recomendam que tem que ser feitos exames laboratoriais e forenses. Deve-se fazer coleta de culturas, material de swab das cavidades oral, vaginal e retal, sorologia para IST/HIV, hepatite, sífilis, tipagem sanguínea, fosfatases e pesquisa de DNA. Amostras para sangue, células epiteliais e sêmen que devem ser colocadas em papel-filtro esterilizado e guardadas em envelopes de papel, enviar sob ofício para Instituto Médico Legal (IML). Quando a vítima não tomou Anticoncepcional de Emergência faz exame sanguíneo e ultrassom para diagnosticar gravidez (Ferriani, 2011).

\subsection{Notificações dos casos}

A notificação dos casos é o primeiro passo dado pelo setor de saúde para responsabilização dos agressores. A situação de violência deve ser comunicada às autoridades competentes, e deve ser compartilhada às informações com os outros profissionais que visam a proteção da vítima (Silva 2011).

Deve ser realizado o atendimento por qualquer profissional de saúde que possa acolher a vítima em risco de situação de violência, preencher folha de notificação de violência, direcionar o paciente para o Núcleo de Prevenção de Violência (NPV) da unidade para o atendimento seja realizado, depois de identificar e realizar o encaminhamento o profissional que compõe o núcleo deve fazer uma entrevista de acolhimento, realizar orientações e encaminhamentos ao paciente. Um ou mais profissionais será a referência do paciente para acompanhamento de todo o processo. O atendimento realizado no setor de 
saúde é encaminhado à vigilância epidemiológica por meio da notificação no Sistema de Informação de Agravos de Notificação (SINAN), que tem como objetivo elaborar a execução de políticas públicas para o enfrentamento da violência. Estudos indicaram falhas na sistematização dos registros e casos, por mais que estejam registrados em prontuários, os dados brutos dificultam o acesso rápido das informações. Isso mostra pouca qualidade tanto na valorização dos registros como também a necessidade de capacitação dos profissionais. A notificação é necessária e é um ato de cuidado, contribui para adotar medidas adequadas de proteção, tanto do profissional quanto da vítima da violência e de seus familiares. (EGRY, 2018)

\subsection{Atuação da enfermagem}

Antes do $5^{\circ}$ dia após a violência sexual, a enfermagem deve acolher o paciente levar ao consultório reservado, oferecer apoio, escuta ativa e explicar os riscos de gravidez, infecções por IST/HIV e as prevenções disponíveis. Preparar para consulta com médico, fazer exame físico e ginecológico com possíveis coleta de matérias, orientar sobre coleta de sangue para sorologia de HIV, sífilis e hepatite B e C, administrar medicamentos seguindo o protocolo, solicitar kit violência, orientar que se houver êmese até às duas horas da ingestão do Anticoncepcional de Emergência deve ser repetida, Explicar sobre os sintomas de intolerância aos antirretrovirais; orientar cuidados com feridas se caso tiver lesões; orientar que paciente fique atento se tiver infecções geniturinárias, acionar o serviço social e psicólogos. A partir do $6^{\circ}$ dia após a violência a enfermagem deve explicar sobre os riscos que paciente tem de apresentar IST, HIV/AIDS e possível gravidez; solicitar consulta médica, solicitar consulta ginecológica; acolher os familiares e fazer orientações do atendimento imediato (SMS SP, 2012).

\subsection{Importância do vínculo profissional de enfermagem e paciente}

O profissional de enfermagem realiza os cuidados de forma científica e integral, criando um vínculo de confiança, e tem que expressar e agir de forma verdadeira e sincera para que o paciente se sinta bem. As vítimas procuram o serviço de saúde não só para aplicação de protocolos, mas sim receber um atendimento digno e respeitoso, com um acolhimento que dê um norte para não sofrer mais aquele tipo de violência. É muito importante também que o profissional tenha uma escuta ativa, que possa permitir que a vítima exponha seus problemas, e aliviar as tensões, trabalhar a autoestima, autoconfiança, encorajá-la a buscar alternativas de melhoria. Esse é o papel da enfermagem no atendimento (Netto et al, 2018).

\subsection{Dificuldades enfrentadas pela equipe de enfermagem}

Alguns profissionais não se envolvem em casos de violência com medo de demandas judiciais, como o chamado para prestar depoimento, ficam preocupados com medo dos agressores ou familiares dos agressores vingarem-se. Porém diante dos riscos o serviço deve esclarecer os profissionais e criar condições para que atuem com segurança. As responsabilidades compartilhadas entre o profissional que atende o paciente e o notificante é apontado como meio de proteção ao notificante. Lembrando que quando notificado não significa que encerra a atuação do enfermeiro na atenção à vítima, o profissional deve continuar acompanhando. O código de ética de enfermagem considera dever do profissional de seus pacientes em situações graves, e configura como justa causa se o profissional não comunicar a situação de violência às autoridades competentes (Silva, 2011).

Um dos grandes problemas e a qualificação, para o enfrentamento da violência sexual precisa que o profissional tenha qualificação e, a falta e um descompasso entre a atuação do enfermeiro e as necessidades das vítimas. Os ensinos superiores são os responsáveis por essa qualificação. O suporte seria estímulos a ações, como campanhas e eventos sobre o tema. As instituições de saúde também são responsáveis por essa qualificação, sendo que a educação permanente necessária, deve haver parcerias com universidades, que permite a troca de experiências entre profissionais e docentes (Silva, 2011). 


\section{Metodologia}

Este estudo constitui-se de uma revisão da literatura especializada, com abordagem narrativa. Trata-se e uma revisão baseada em produções recentes, podendo empregar fontes de informações bibliográficas ou eletrônicas entre outros (Rother, 2007: Schwartz et al, 2020). Realizada no período de agosto de 2019 a junho de 2020, no qual foi realizada uma consulta a livros periódica presente na biblioteca da Faculdade de Palmas (FAPAL) - campus Palmas- TO e por artigos científicos selecionados através da busca nos bancos de dados da Scielo (Scientific Electronic Library Online), Biblioteca da saúde(BVS) e Ministério da saúde. A busca de dados foi realizada através de descritores: Assistência de enfermagem, violência sexual, vítimas de violência. Foram considerados os critérios de seleção:

(a) Texto completo da publicação disponível;

(b) procedência nacional; (c) período de 2005 a 2019 (d) conteúdos relacionados a assistência de enfermagem, vítimas de violência sexual e vítimas de violências. (e) idioma português. Sendo então desconsiderados os textos que não contemplaram os critérios a, b, c, d, e, e supracitados.

No total foram 14 artigos selecionados, estes estão consolidados no quadro abaixo. A seleção foi através dos bancos de dados da Scielo e foram escolhidos 10 artigos, de Revista científicas foi utilizado 01 artigo e da base de dados da BVS foram escolhidos 03 artigos.

Quadro 1: Artigos utilizados para construção da revisão.

\begin{tabular}{|c|c|c|c|c|}
\hline Bases de dados & Título & Autor & Ano & Considerações \\
\hline Scielo & $\begin{array}{l}\text { Assistência multiprofissional à } \\
\text { vítima de violência sexual: a } \\
\text { experiência da Universidade } \\
\text { Federal de São Paulo }\end{array}$ & Abrahão et al & 2007 & $\begin{array}{l}\text { Destaca a assistência de vários profissionais } \\
\text { no atendimento à mulher vítima de } \\
\text { violência sexual. }\end{array}$ \\
\hline Scielo & $\begin{array}{l}\text { Violência sexual: caracterização } \\
\text { e análise de casos revelados na } \\
\text { escola }\end{array}$ & $\begin{array}{l}\text { Viodres Inoue et } \\
\text { al }\end{array}$ & 2008 & $\begin{array}{l}\text { Descreve uma análise de casos de } \\
\text { violência ocorridas dentro de uma escola e } \\
\text { as consequências desses episódios. }\end{array}$ \\
\hline $\begin{array}{l}\text { Revista Eletrônica } \\
\text { de enfermagem }\end{array}$ & $\begin{array}{l}\text { Assistência à vítima de } \\
\text { violência sexual: a experiência } \\
\text { da Universidade de Taubaté }\end{array}$ & Araújo et al., & 2008 & $\begin{array}{l}\text { O estudo evidencia que a mulher vítima } \\
\text { de violência sexual deve manter } \\
\text { acompanhamento } \\
\text { especializado. }\end{array}$ \\
\hline Scielo & $\begin{array}{l}\text { Significado da violência sexual } \\
\text { na manifestação da } \\
\text { corporeidade: um estudo } \\
\text { fenomenológico }\end{array}$ & Labronici et al & 2010 & $\begin{array}{l}\text { Descreve o impacto da violência sexual na } \\
\text { vida da mulher e suas consequências. }\end{array}$ \\
\hline Scielo & $\begin{array}{l}\text { O cuidar em enfermagem à } \\
\text { mulher vítima de violência } \\
\text { sexual }\end{array}$ & Morais et al & 2010 & $\begin{array}{l}\text { A assistência de enfermagem é } \\
\text { fundamental no cuidado à mulher } \\
\text { violentada. }\end{array}$ \\
\hline Scielo & $\begin{array}{l}\text { Atuação da enfermagem frente à } \\
\text { violência sexual contra crianças e } \\
\text { adolescentes }\end{array}$ & Ferriani et al & 2011 & $\begin{array}{l}\text { Descreve a importância do enfermeiro no } \\
\text { atendimento a vítimas de violência sexual, } \\
\text { com humanizacão da assistência. }\end{array}$ \\
\hline BVS & $\begin{array}{l}\text { A clínica em situações de abuso } \\
\text { sexual: aspectos conceituais e } \\
\text { atuação } \\
\text { interdisciplinar }\end{array}$ & Drezett et al & 2012 & $\begin{array}{l}\text { O cuidado clínico é indispensável para } \\
\text { prevenir agravos à saúde da pessoa que } \\
\text { sofreu violência sexual. }\end{array}$ \\
\hline Scielo & $\begin{array}{l}\text { Notificação da violência como } \\
\text { estratégia de vigilância em } \\
\text { saúde: perfil de uma } \\
\text { metrópole do Brasil }\end{array}$ & Veloso et al & 2013 & $\begin{array}{l}\text { Relata a incidência da violência sexual no } \\
\text { Brasil e descreve estratégias de vigilância. }\end{array}$ \\
\hline Scielo & $\begin{array}{l}\text { Violência sexual: estudo } \\
\text { descritivo sobre as vítimas e o } \\
\text { atendimento em um serviço } \\
\text { universitário de referência no } \\
\text { Estado de São Paulo, Brasil }\end{array}$ & Facuri et al & 2013 & $\begin{array}{l}\text { Estudo a respeito de como o profissional } \\
\text { deve proceder no atendimento de vítimas } \\
\text { de violência sexual. }\end{array}$ \\
\hline BVS & $\begin{array}{l}\text { Violência sexual contra } a \\
\text { mulher: Histórico e conduta }\end{array}$ & Porto et al & 2014 & $\begin{array}{l}\text { Revela o histórico de violência contra a } \\
\text { mulher e mostra os avanços no combate a }\end{array}$ \\
\hline
\end{tabular}




\begin{tabular}{|c|c|c|c|c|}
\hline & & & & este tipo de violência. \\
\hline Scielo & $\begin{array}{l}\text { Violência sexual contra } \\
\text { a mulher e o atendimento no } \\
\text { setor saúde em Santa Catarina }\end{array}$ & Delziovo et al & 2018 & $\begin{array}{l}\text { Atendimento à mulher vítima de violência } \\
\text { e as providências a serem tomadas frente a } \\
\text { este ato. }\end{array}$ \\
\hline Scielo & $\begin{array}{l}\text { Evolução da notificação de } \\
\text { violência sexual no Brasil de } \\
2009 \text { a } 2013\end{array}$ & Gaspar et al & 2018 & $\begin{array}{l}\text { Estudo retrospectivo do cenário da } \\
\text { violência sexual no Brasil e seus agravos. }\end{array}$ \\
\hline BVS & $\begin{array}{l}\text { Atuação da enfermagem na } \\
\text { conservação da saúde } \\
\text { mulheres em situação de } \\
\text { violência }\end{array}$ & Netto et al & 2018 & $\begin{array}{l}\text { O enfermeiro atua frente ao Atendimento } \\
\text { à mulher vítima de violência desde o } \\
\text { acolhimento até sua alta. }\end{array}$ \\
\hline Scielo & $\begin{array}{l}\text { Notificação da violência } \\
\text { infantil, fluxos de atenção e } \\
\text { processo de trabalho dos } \\
\text { profissionais da Atenção } \\
\text { Primária em Saúde }\end{array}$ & Egry et al & 2018 & $\begin{array}{l}\text { Demonstra como o atendimento deve ser } \\
\text { feito na atenção básica, incluindo } \\
\text { procedimentos a serem realizados. }\end{array}$ \\
\hline
\end{tabular}

Fonte: Autoria própria (2020).

A violência sexual é um problema de saúde pública que vêm atingindo um alto número de vítimas, as quais ficam marcadas para sempre. Cabe ao profissional de saúde realizar o acolhimento e prestar uma assistência adequada. Em especial o enfermeiro é o profissional atuante na administração de cuidados humanizados e engloba não só os cuidados mecânicos ao paciente, mas fornece apoio emocional, desenvolvendo suas funções baseadas no respeito, ética e responsabilidade profissional.

\section{Resultados e Discussão}

A pesquisa de dados foi realizada de acordo na base de dados SCIELO foram encontrados 15 artigos científicos; pela base de dados BVS 8 artigos foram escolhidos, pela revista eletrônica de enfermagem foi escolhido 1 artigo, e dados do ministério da saúde.

Diante dos materiais citados, após pesquisa concluída foram escolhidos 10 artigos da base SCIELO, 7 artigos da base BVS, pela revista eletrônica de enfermagem foi escolhido 1 artigo.

Do total de 25 materiais lidos e estudados, foram excluídos 7 artigos que não se enquadraram com a proposta do trabalho com o tema assistência de enfermagem as vítimas de violência sexual. E então 4 matérias foram escolhidas para construção dos resultados e discussões.

Quadro 2: Quadro sinóptico dos artigos selecionados.

\begin{tabular}{|c|c|c|c|c|}
\hline Bases de dados & Título & Autor & Ano & Considerações \\
\hline SCIELO & $\begin{array}{c}\text { Atuação da enfermagem frente à } \\
\text { violência sexual contra crianças e } \\
\text { adolescentes }\end{array}$ & Ferriani et al & 2011 & $\begin{array}{l}\text { O artigo aborda sobre a atuação do } \\
\text { enfermeiro, e a legislação frente a } \\
\text { violência sexual conta crianças e } \\
\text { adolescente. }\end{array}$ \\
\hline BVS & $\begin{array}{l}\text { Prevenção e tratamento dos agravos } \\
\text { resultantes da violência sexual } \\
\text { contra mulheres e adolescentes }\end{array}$ & Pedrosa & 2012 & $\begin{array}{c}\text { A caderneta aborda sobre prevenção e } \\
\text { tratamento dos problemas que acarreta } \\
\text { a violência sexual contra mulheres e } \\
\text { adolescentes. }\end{array}$ \\
\hline BVS & $\begin{array}{c}\text { Normas técnicas atenção } \\
\text { humanizada as pessoas em situação } \\
\text { de violência sexual com registros de } \\
\text { informações e coleta de vestígios }\end{array}$ & Passos et al & 2015 & $\begin{array}{c}\text { A caderneta aborda todas as normas } \\
\text { humanizadas das pessoas que sofrem } \\
\text { violência sexual e registro de } \\
\text { informações. }\end{array}$ \\
\hline SCIELO & $\begin{array}{c}\text { Evolução da notificação de violência } \\
\text { sexual no Brasil de } 2009 \text { a } 2013\end{array}$ & Gaspar et al & 2018 & $\begin{array}{l}\text { O artigo citado aborda a evolução das } \\
\text { notificações de violência sexual que } \\
\text { ocorreram entre } 2009 \text { a } 2013 \text { no Brasil. }\end{array}$ \\
\hline
\end{tabular}

Fonte: Autoria própria (2020). 
A violência sexual tem como principal vítima as mulheres, em todas as faixas etárias, por mais que o homem sofra esse tipo de violência, sempre prevaleceu o sexo feminino. Esse é um reflexo de origens históricas relacionadas a posição em que o homem e a mulher devem supostamente assumir na sociedade. Quando o agressor é alguém próximo da vítima, quando existe um vínculo, a vítima acaba adiando para procurar ajuda, e geralmente o agressor tem um relacionamento de confiança e poder sobre a vítima, sendo pai, padrasto, alguém da família ou amigos (Gaspar et al, 2018).

Quando a vítima procura ajuda a rede de saúde pode ser uma das primeiras oportunidades para a vítima revelar que está em situação de violência. O diagnóstico da situação deve ser reconhecido pelo profissional, fazendo perguntas e investigando a hipótese diagnóstica. A confidência e o compromisso são essenciais para garantir a confiança para que a vítima se sinta à vontade, não só na revelação da situação de violência, mas também para dar continuidade ao atendimento. No atendimento tem que garantir o sigilo, o profissional envolvido deve adotar uma postura ética, deve ter cuidado com a utilização de prontuários, anotações, e tem que ter a comunicação adequada com os membros da equipe (Pedrosa et al, 2012).

$\mathrm{O}$ acolhimento e a escuta também são muito importantes para o atendimento das vítimas. $\mathrm{O}$ acolhimento deve ser digno e respeitoso, a escuta, a aceitação das diferenças o reconhecimento, respeitar as decisões da vítima, devemos escutar sem julgá-los, ter disposição para lidar com os conflitos, valorizar as queixas, identificar necessidades, e procurar ter empatia, são pontos básicos que poderão ajudar a vítima a falarem das suas necessidades e sentimentos (Passos et al, 2015).

Mas para o profissional ter todas essas qualidades citadas acima, para o enfrentamento da violência sexual o profissional deve estar qualificado, para tal demanda. A falta de qualificação é um dos problemas que causa um descompasso entre a atuação do profissional e as necessidades das vítimas. As instituições apontadas responsáveis pelo suporte da qualificação são: instituições de saúde, ensino superior, as duas em parceria permitiriam troca de experiências entre profissionais da assistência e os docentes (Ferriani 2011).

\section{Considerações Finais}

De acordo com o estudo realizado em cima do tema assistência de enfermagem as vítimas de violência sexual, podese concluir que é a violência de gênero mais terrível que ocorreu no passado e atualmente ainda acontece, é muito importante que as vítimas sintam-se a vontade em procurar ajuda nos serviços de saúde ou em delegacias, Segundo os estudos percebe-se que aos poucos o número de notificações estão aumentando as vítimas estão cada vez mais ativas em compartilhar e procurar ajuda.

Em relação aos profissionais enfermeiros percebe-se que existe muita dificuldade em atender as vítimas por falta de preparo, medo, tabu, desejo de revanche, impotência na resolução dos casos, sofrem culpa entre outros. O profissional de enfermagem deve realizar o cuidado, criando vínculo de confiança, e expressar no cuidado, atitudes verdadeiras e sinceras para o paciente sentir-se seguro, dar motivação para a vítima vencer os agressores.

O enfermeiro é o profissional que está apto a prestar uma assistência qualificada a mulher vítima de violência sexual, sendo responsável por prestar uma escuta qualificada, e administrar além dos cuidados técnicos, saber ouvir as queixas da paciente é fundamental, no estabelecimento do cuidado integral, humanizado, respeitando as particularidades de cada, mantendo o respeito e oferecendo o apoio emocional.

O profissional de enfermagem durante suas consultas deve realizar o acolhimento, desde de sua chegada no serviço de saúde, desde sua saída, percorrendo todo processo, passando o sentimento de segurança e proteção à mulher, garantindo o sigilo, respeitando suas escolhas sem julgamentos, zelando pelo seu bem-estar e realizando os encaminhamentos adequados.

É importante também que o profissional compartilhe as decisões, dúvidas e sentimentos com a equipe. Enfim, o papel do enfermeiro é acolher o paciente de forma humanizada, avaliando, fazendo anamnese, exames físicos diagnosticar, tratando 
os agravos, orientando, encaminhando e notificando. A assistência de enfermagem envolve a ação de acolher, escutar e tratar e deve ser centrada na promoção, proteção e recuperação da saúde.

\section{Referências}

Abrahão, A. R., et al. (2007). Assistência multiprofissional à vítima de violência sexual: a experiência da Universidade Federal de São Paulo. Cad. Saúde Pública, 23(2):459-464

Araújo, C. A. A., Faria, A. L. \& Baptista, V. H., (2008). Assistência à vítima de violência sexual: a experiência da Universidade de Taubaté. Rev. Eletr. Enf. 10(4):1138-43. http://www.fen.ufg.br/revista/v10/n4/v10n4 a26.htm.

Delziovo, C. R.; et al. (2018). Violência sexual contra a mulher e o atendimento no setor saúde emSanta Catarina - Brasil. Ciência \& Saúde Coletiva, 23(5):1687-1696.

Drezett, J. (2012) A clínica em situações de abuso sexual: aspectos conceituais e atuação interdisciplinar. O Mundo da Saúde, São Paulo -;36(2):346-350.

Egry, E. Y., Apostolico, M. R., Morais, T. C. P (2018). Notificação da violência infantil, fluxos de atenção e processo de trabalho dos profissionais da Atenção Primária em Saúde. Ciência \& Saúde Coletiva, 23(1): 83-92.

Facuri, C. O. (2013). Violência sexual: estudo descritivo sobre as vítimas e o atendimento em um serviço universitário de referência no Estado de São Paulo, Brasil. Cad. Saúde Pública, 29(5):889-898.

Faria, A. L., Araújo, C. A. A. \& Baptista, V. H. (2008). Assistência à vítima de violência sexual: a experiência da Universidade de Taubaté. Rev. Eletr. Enf. [Internet].;10(4):1138-43. Disponível em: http://www.fen.ufg.br/revista/v10/n4/v10n 4a26.htm.

Ferriani, M. G. C., Silva, L. M. P.; et al (2011). Atuação da enfermagem frente à violência sexual contra crianças e adolescentes. Rev Bras Enferm, Brasília 2011 set-out; 64(5): 919-24. Acessado 30 de abril de 2020.

Gaspar, R. S. \& Pereira, M. U. L. (2018). Evolução da notificação de violência sexual no Brasil de 2009 a 2013. Cad. Saúde Pública; $34(11)$ :e00172617.

Gomes, A. V., Ferreira, R. K. A., \& Rodrigues, C. F. do C. (2020). A saúde na vida do cárcere no Brasil e no Tocantins. Research, Society and Development, 9(9), e981998067. https://doi.org/10.33448/rsd-v9i9.8067

Huculak, M. Ferreira, M. C. F., \& Tchaikovski, H. L. D (2017). Protocolo para o atendimento às pessoas em situação de violência sexual / SAS. (2a ed.), Sesa, 2017. pp10.

Labronici, L. M., Fegadoli, D., \& Correa, M. E. C. (2010). Significado da violência sexual na manifestação da corporeidade: um estudo fenomenológico. Rev Esc Enferm USP; 44(2):401-6 www.ee.usp.br/reeusp/.

Morais, S. C. R. V. Monteiro, C. F. S. \& Rocha, S. S. (2010). O cuidar em enfermagem à mulher vítima de violência sexual. Texto Contexto Enferm, 19(1): 155-60.

Netto, L. A.; et al. (2018). Atuação da Enfermagem na Conservação da Saúde de Mulheres em Situação de Violência. Reme • Rev Min Enferm. $22:$-1149.

Passos, A. S., et al. (2015). Norma técnica atenção humanizada às pessoas em situa ção de violência sexual com registro de informações e coleta de vestígios

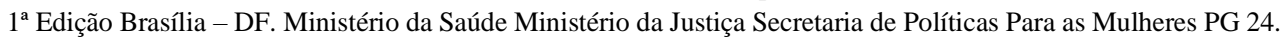

Pedrosa, A. A. G., et al. (2012). Prevenção e tratamento dos agravos resultantes da violência sexual contra mulheres e adolescentes. Ministério da Saúde. $3^{a}$ edição atualizada e ampliada $1^{\mathrm{a}}$ reimpressão. Série A. Normas e Manuais Técnicos Série Direitos Sexuais e Direitos Reprodutivos - Caderno no 6 . Brasília DF, p 32 e 44.

Portela, A. P. (2014). Prevenção e tratamento dos agravos resultantes da violência sexual contra mulheres e adolescentes. Norma Técnica. $3^{\text {a }}$ edição atualizada e ampliada $2^{a}$ reimpressão Série Direitos Sexuais e Direitos Reprodutivos - Caderno nº 6. Brasília - DF. PG,9.

Porto, M. L.; \& Amaral, W. N. (2014). Violência sexual contra a mulher: Histórico e conduta Femina. 42(4).

Rocha, C. C., Lima, T. S., Silva, R. A. N., \& Abrão, R. K. (2020). Abordagens sobre sífilis congênita. Research, Society and Development, 9(8), e984986820. https://doi.org/10.33448/rsd-v9i8.6820

Rodrigues, C. F. do C., Silva, M. da V. F. B., Souto, L. F. de S., Silva, E. A. A. da, Mocelai, R. S., Rodrigues, A. L. M., Coelho, S. C. D., \& Abrão, R. K. . (2020). Promoção de saúde para mulheres em território de vulnerabilidade social: comunidade a Saroba. Research, Society and Development, 9(10), e8159109116. https://doi.org/10.33448/rsd-v9i10.9116

Rodrigues, C. F. do C., Alves, M. M. M., Brustulin, R., \& Ferreira, R. K. A. (2020). Avaliação do Controle do HIV/Aids na Atenção Primária em Palmas/TO. Research, Society and Development, 9(9), e372997126. https://doi.org/10.33448/rsd-v9i9.7126 
Research, Society and Development, v. 11, n. 2, e38011225817, 2022

(CC BY 4.0) | ISSN 2525-3409 | DOI: http://dx.doi.org/10.33448/rsd-v11i2.25817

Rother, E. (2007). "Brasil - Revisão sistemática X revisão narrativa Revisão sistemática X revisão narrativa." SciELO, Acta Paulista de Enfermagem, https://www.scielo.br/j/ape/a/z7zZ4Z4GwYV6FR7S9FHTByr/?lang=pt.

Schwartz, S., Vieira, M. A.., Rodrigues, A. C. S., \& Ferreira, R. K. A. (2020). Estratégias para o trabalho com textos na universidade. Research, Society and Development, 9(8), e790986209. https://doi.org/10.33448/rsd-v9i8.6209

Secretaria de saúde do governo do Tocantins 2015. Savis oferece atendimento 24 horas a vítimas de violência. https://saude.to.gov.br/noticia/2015/11/4/savisoferece-atendimento-24-horas-a-vitimas-de-violencia/ .

Secretaria municipal de São Paulo, 2012. Prefeitura de São Paulo, Secretaria Municipal de Saúde, Hospital Municipal e Maternidade Escola Dr. Mário De Moraes Altenfelder Silva Vila Nova Cachoeirinha. Coleção Protoco Los Hmec 2012 - Normas E Rotinas Para o Atendimento das Vítimas de Violência Sexual. São Paulo JUNHO/2012 $1^{\text {a }}$ EDIÇÃO. PGS 14, 15 e 16.

Silva, M. A. I., Ferriani, M. G. C.; et al. (2011). Atuação da enfermagem frente à violência sexual contra crianças e adolescentes. Rev Bras Enferm, 64(5): 91924.

Veloso, M. M. X. (2013). Notificação da violência como estratégia de vigilância em saúde: perfil de uma metrópole do Brasil. Ciência \& Saúde Coletiva, 18(5):1263-1272.

Viodres, Inoue, S. R. \& Ristum, M. (2008). Violência sexual: caracterização e análise de casos revelados na escola. Estudos de Psicologia I Campinas I 25(1) I $11-21$

Yamamoto, A. (2015). Norma técnica atenção humanizada às pessoas em situação de violência sexual com registro de informações e coleta de vestígios. ministério da saúde ministério da justiça secretaria de políticas para as mulheres. p 9. 